\title{
An exploratory study on application of WhatsApp for enhancing language learning skills in multicultural environment
}

\author{
Muskan Solanki*, Naveen Kumar Mehta**, Dharmendra Mehta*** \\ *Sanchi University of Buddhist-Indic Studies, Barla, India; muskan.http@gmail.com \\ **Sanchi University of Buddhist-Indic Studies, Barla, India; nknmehta@gmail.com \\ ***Pt JNIBM and HOD S.S. in Commerce, V.U., Ujjain, India; shardadnm28@gmail.com
}

\begin{abstract}
Language learning cannot be done in isolation as it is a social process and helps in interacting with people of diverse culture and tradition. This Multiculturalism enables any language to become more alive, vibrant and meaningful. In today's context; social media applications or software, undoubtedly, directly or indirectly strengthens the process of language learning in multicultural milieu. The application of WhatsApp is growing at a very fast pace across the globe. It is gaining popularity among students as it enhances the LSRW skills in a multicultural and multilingual environment. English as a language has occupied a very prominent place in Indian society. As a Lingua Franca, it is being used by a great number of Indians and this number is increasing steadily but gradually. It is emerging as a link language for the people of North, South, East, and West, where regional languages like Tamil, Telugu, Gujarati, Marathi, Bengali, and Kannada are widely spoken along with regional dialects. In this background, the present exploratory study discusses the application of WhatsApp for enhancing language learning skills in multicultural environment.
\end{abstract}

Keywords: language, learning, multicultural, multilingual, environment, WhatsApp, English

\section{Introduction}

The country like India is known for Unity in Diversity and since time immemorial it is an abode of various cultures and traditions. By keeping this fact in mind, the ancient Grammarians like Pānini and Bhartrhari have also put emphasis on learning a language in a natural setting and thereby focusing on word and sound. Pannini was of the opinion that the meaning of the word is bound to change by the passage of time as also in varying contexts. The users who use the language in their mundane affairs are, therefore, the best judges who derive meaning from the words. On the other hand, Bhartrhari accepts that a word is vital in any sentence and can have multiple meanings. He propounded the theory of Sphoța and it is the real experience of listening to a sentence and obtaining its multiple layers of meaning through perception. It is not something that can be inferred but something that can be perceived. The role and particular desired meaning of the word largely looms upon the intent of the speaker and the environment in which it is implied. (Hrodrigues 2008)

According to Dictionary of Literary Terms and Literary Theory, Multiculturalism refers to a broad range of intellectual and political movements initiated by various ethnic and religious minorities, feminists and gays during the last two or three decades of the twentieth century. (Penguin Books, 2013) It is the coexistence of diverse cultures, where culture includes racial, religious, or cultural groups and is manifested in customary behaviors, cultural assumptions and values, patterns of thinking, and communicative styles.

In recent years, especially in rural and urban areas of India after the introduction of Android phones, people have started using social platforms like Twitter, Facebook, WhatsApp, Instagram, WeChat, Hike, and Telegram and so on. These platforms have given momentum to the exchange of information and connectivity to the rest of the world. According to Mehta, Mobile Assisted Language Learning (MALL) is very helpful in honing language skills Teaching of English as a Second Language (2012). Out of these Apps, WhatsApp has emerged as the most favorable app amidst the masses. Especially, the young generation is conversant with its multiple applications. It has gained popularity in no time by leaps and bounds as it is user-friendly and has got various features through which users can share all kinds of 
information and messages in no time. It is observed that the previous studies were mostly having their focus on conceptual framework and based on language learning through IT enabled tools but only a few studies have been attempted on the application of WhatsApp in learning process so, in this context, the present research study may prove to be significant for the academic institutions, educators, trainers and for learners as well to explore new ways of learning through WhatsApp.

The use of WhatsApp is growing across the globe and according to the latest information available from different resources, approximately two billion people are using WhatsApp and it is the second largest social platform/social network after Facebook. Among students, it is quite popular as they are very familiar with the varied features of WhatsApp. The one of the most important aspects of this social media application is that it enables the users to have face to face communication/interaction through video calling which is earlier possible only in the physical presence of both the parties. The other important aspect of it is that it is accessible twenty-four into seven into three sixty-five days, irrespective of any geographical and cultural distances. It is also a boon for creating collaboration through different groups in a closed space to reach to a large number of users. Thus, it covers a large number of area and masses. In ELT (English Language Teaching) environment, the use of WhatsApp is growing its visibility and acceptance. WhatsApp clusters can be created in ELT Classrooms for working in collaborative manner and overcoming challenges of multicultural and multilingual environment. In India, around four hundred million people are using WhatsApp due to its user-friendly features. According to Patel, the ultimate goal of multimedia language teaching is to promote students' motivation and learning interest, which can be a practical way to get them involved in the language learning. The process of English communication learning will be more student-centered but less time-consuming. Therefore, the teaching quality will be improved and students' applied English communication can be effectively cultivated (2013).

\section{Some key usages of WhatsApp for language learning in multicultural environment}

Following are the main usages of WhatsApp for language learning in multicultural environment for the teachers and learners as well

\section{For the teachers}

- For creating a congenial learning environment;

- For developing a sense of belongingness for the culture of the self as well as respect and regard for others' culture;

- For making language learning challenging, live, interesting and convenient;

- For using IT and software based technology for making language learning effective and impressive;

- For sharpening all the basic four language learning skills;

- For organizing group and peer activities for increasing active participation of learners.

For the learners

- In understanding and sharing information in powerful, fast and effective manner;

- In reaching, sharing and understanding the socio-cultural environment of others;

- In improving relationship and developing a sense of better understanding;

- In providing positive and prompt feedback;

- In enhancing all the basic four language learning skills in a very challenging multicultural environment for personal and professional growth;

- In using technology for making process of language learning convenient, accessible and pragmatic.

\section{Review of literature}

Mehta (2012) discussed the ways in which mobile phone technology can be incorporated in learning English language. Patel (2013) analyzed the necessity of multimedia technology in communication skill 
teaching and also brings out the problems faced by using these technologies. It also aims to make English teachers aware of the strategies to use it in an effective manner. Bansal and Joshi (2014) studied the attitude of the students towards WhatsApp learning.

Rathore and Mehta (2015) explored the sharpening communication skills of engineering students via multifaceted digital tools. Said (2015) determined the effectiveness of using a WhatsApp Messenger as one of mobile learning technique to develop students' writing skills. Maria (2016) identified whether the use of social networking sites or applications can help motivate undergraduate college level L2 learners of English to use their reading and writing skills thus enhancing their skills with reduced anxiety.

Srilakshminarayana (2016) examined the preference level of the students given to the app as compared to traditional means of communication and also among the social networks and studied the perception of students on the usage of the app in daily communication and for specific academic related activities and to Identify the factors that motivate students prefer the usage of WhatsApp for communication.

Naveen and Sudhansh (2016) investigated the behavior of WhatsApp users and reflect the possible ways in which WhatsApp can be helpful in education, social services and governance. Mona (2017) discussed the factors in which WhatsApp is useful to enhance students learning and enthusiasm as it helped students to develop English skills, enriched their vocabulary and learn from their mates' mistakes. Mohammad (2017) found out the effect of using "WhatsApp messenger" in learning English language among university students.

Khaled (2018) highlighted the perceptions of WhatsApp among EFL Students, and its potential benefits in ELT practicum. Pratika (2018) studied the impact of using WhatsApp by exploring, describing and analyzing students' opinion in learning English through WhatsApp. Elias (2018) examined perception about using WhatsApp in learning vocabulary. Ali, Patintingan and Indahyanti (2018) revealed that the use of WhatsApp is highly supporting in learning outside the classroom as it provides varied progress. Jaroslav (2019) studied whether mobile applications used in the learning of English as a foreign language are beneficial and/or effective.

\section{Research methodology and objectives}

India is primarily known as the land of villages where more than seventy percent of its population lives in villages. India is a vast country and has various languages, cultures, and traditions and value norms. Learning any language in such a diverse multicultural background is quite challenging and interesting too. Madhya Pradesh is located in the heart of India and the most used language of this state is Hindi and its related varied forms of dialects. To cater to the growing demands of the professional world and keeping pace with the changing time, English is being taught from Nursery level in all the schools (Public and Private). The impact of Mother tongue is quite apparent in the use of language. There is no standard form of English in practice that can be followed and practice across the state.

The present study is conducted during September-October 2019 in a Graduate College of Bhopal, capital of Madhya Pradesh. A well-structured questionnaire was prepared on the basis of literature review with close-ended questions. After each stage, feedback was obtained and then questionnaire was modified. Majority of the feedback from the experts provided positive remarks and certified that the questionnaire was acceptable for data collection. The questionnaire was distributed among eighty students. Out of which, fifty-six questionnaires were returned and finally fifty fully filled questionnaire were taken for this study. Out of fifty respondents, twenty-nine are boys and twenty-one are girls. They belonged to the age group ranging from eighteen to twenty-one years. The Random Sampling method is used for conducting the present study. This method was used because it was not known previously as to whether a particular student will be asked to fill the questionnaire. Considering the constraints, it was decided to conduct the study based on sample size of 50 respondents. Also the basic aim of doing the research was academic; hence most convenient way was selected. The questionnaires were collected, 
responses were recorded, tabulated, analyzed and on the basis of that conclusions were drawn and suggestions were provided.

In this research both primary and secondary data has been used. Primary data has been collected from students studying in ABC College of Bhopal. Primary data has been collected through survey method. The primary data is collected on the response received from the given questionnaires. The secondary information was collected through newspapers, journals, magazines and websites. The objectives of the present study are to discuss the features of WhatsApp for enhancing LSRW Skills (Listening, Speaking, Reading, Writing), to review the literature related to the use of multimedia technology in language learning and to study the impact of multicultural environment in language learning.

\section{Data analysis}

The respondents were given questionnaires to share their experience of using WhatsApp as a tool, for enhancing their language learning skills and collected questionnaires were thoroughly reviewed, recorded and analyzed.

Figure 1: Which Social App do you use for your communication?

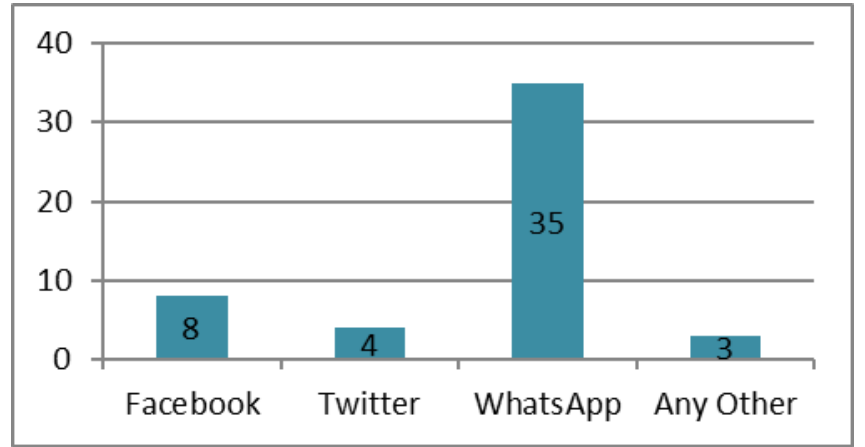

Source: Data collected through questionnaire

The result clearly indicates that the number of WhatsApp users is higher than any other social media application. It is revealed that for communication WhatsApp is more user-friendly, easy, accessible and effective. Facebook and Twitter secured second and third place respectively.

Figure 2: State to what type of WhatsApp Group are you associated with?

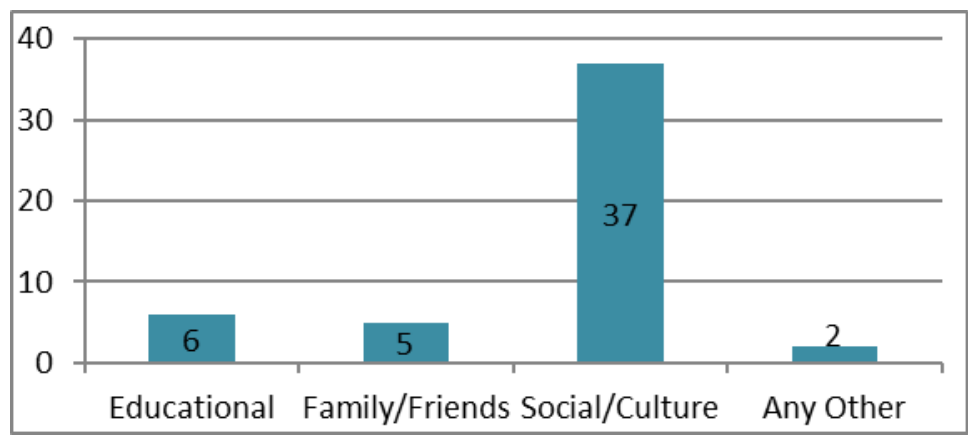

Source: Data collected through questionnaire

More than seventy percent of respondents have responded that they are associated with sociocultural group which is followed by Educational/Informative group on the second spot. Family/Friends group is also very popular among students and it secured third place. 
Figure 3: Which language do you prefer while transmitting information on WhatsApp?

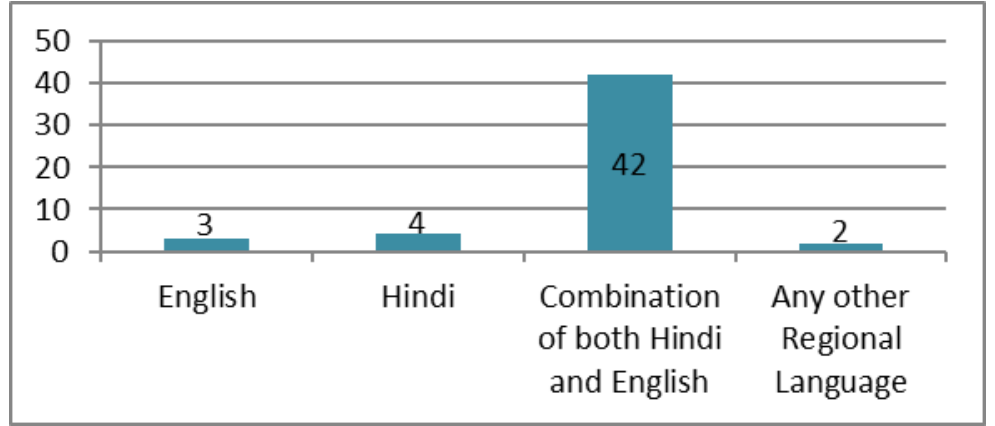

Source: Data collected through questionnaire

The result reveals that mostly students favored combination of both Hindi/English as their language for transmitting information through WhatsApp. Hindi and English language secured second and third spot respectively. The other regional languages are least preferred by the respondents.

Figure 4: How many hours do you spend on WhatsApp?

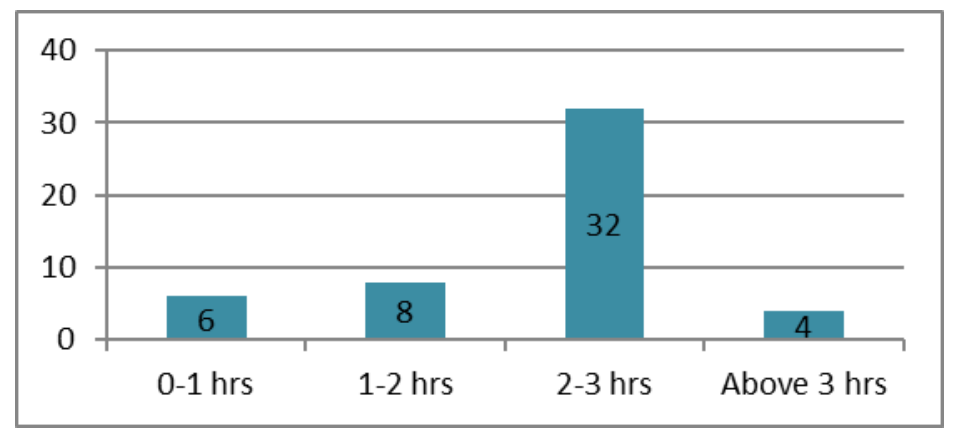

Source: Data collected through questionnaire

The results clearly indicate that mostly students spent at least two to three hours per day on WhatsApp. Though, very less percent of respondents spent more than three hours using WhatsApp.

Figure 5: In which format do you transmit information on WhatsApp?

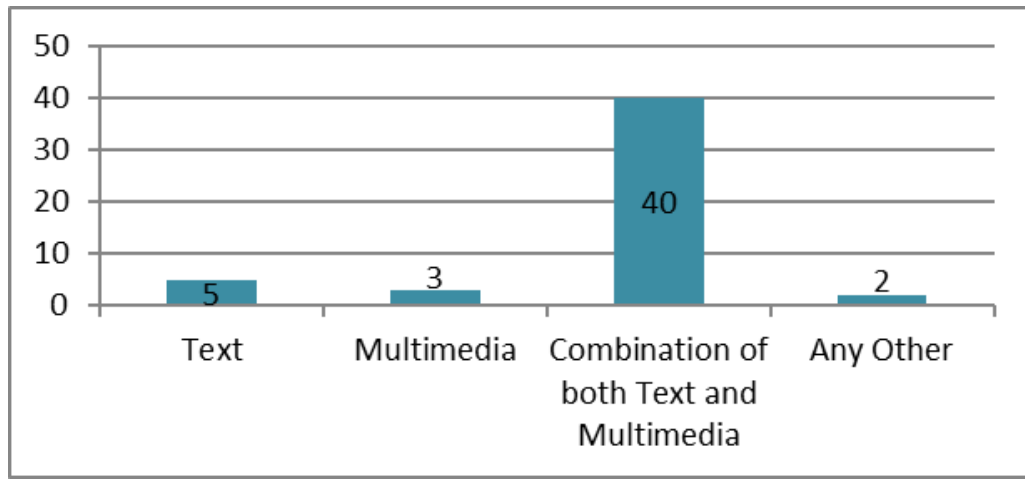

Source: Data collected through questionnaire 
The results reveal that eighty percent of the respondents have preferred combination of both text and multimedia for transmitting information on WhatsApp. After this, respondents preferred the medium of text, multimedia and other respectively.

Figure 6: Application of WhatsApp is helpful for.

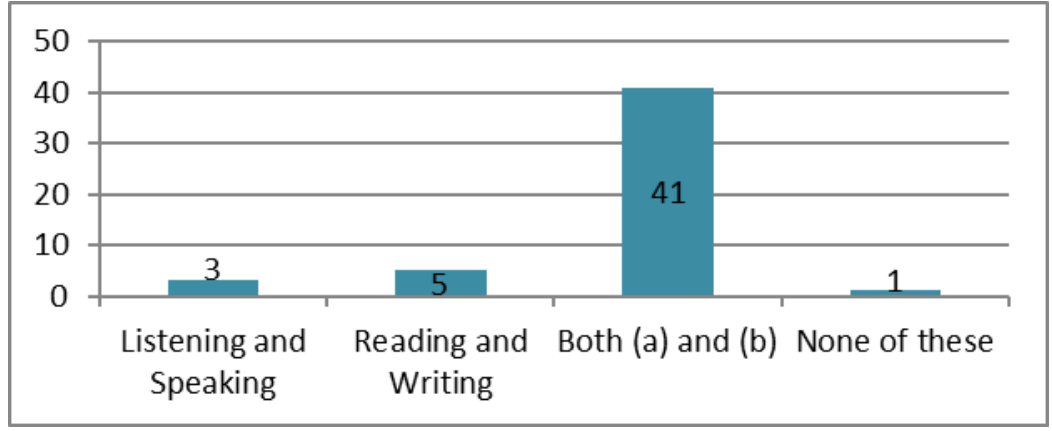

Source: Data collected through questionnaire

More than seventy-nine percent of respondents find that application of WhatsApp enables them to develop their latent skills.

Figure 7: The effective use of language through WhatsApp helps in.

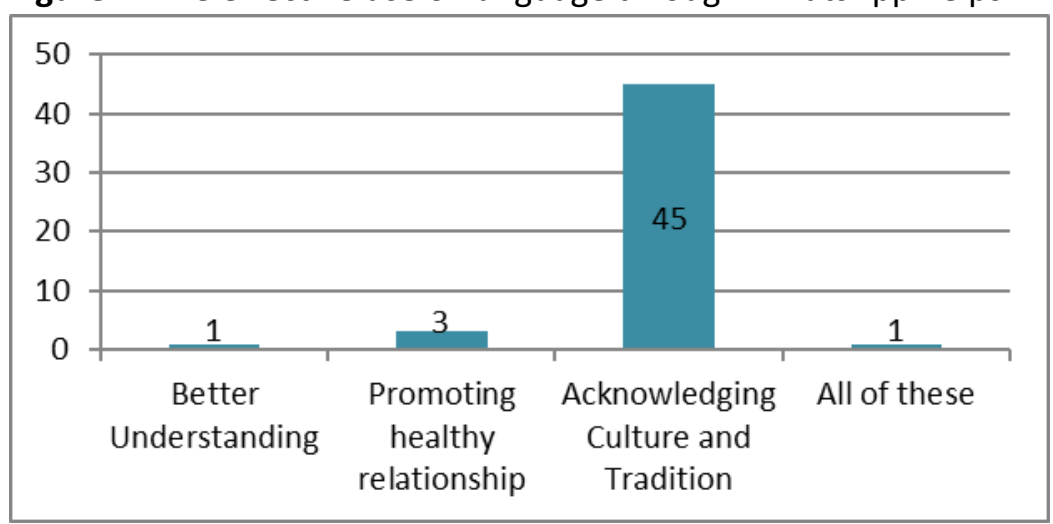

Source: Data collected through questionnaire

The result clearly indicates that the effective use of language through WhatsApp adds in acknowledging culture and tradition in a deeper way. Ninety percent of the respondents agree that WhatsApp helps in acknowledging culture and tradition.

Figure 8: Application of WhatsApp is useful in enhancing listening, speaking, reading, and writing skills.

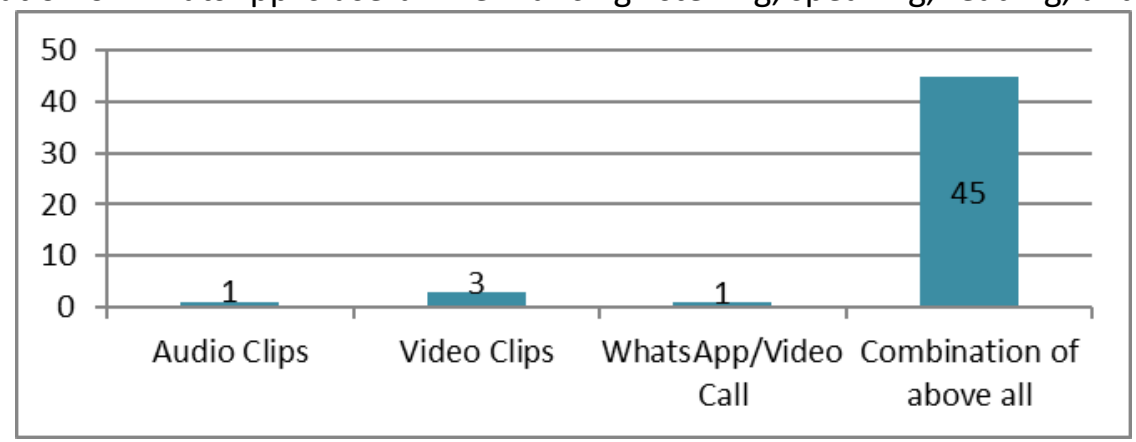

Source: Data collected through questionnaire 
Ninety percent of respondents feel that combination of audio and video clips as well as WhatsApp/Video call helps them to listen with more accuracy, to speak with more confidence, reading with deeper understanding and writing flawlessly and with less grammatical errors in language.

Figure 9: How do you understand and promote others culture while using WhatsApp?

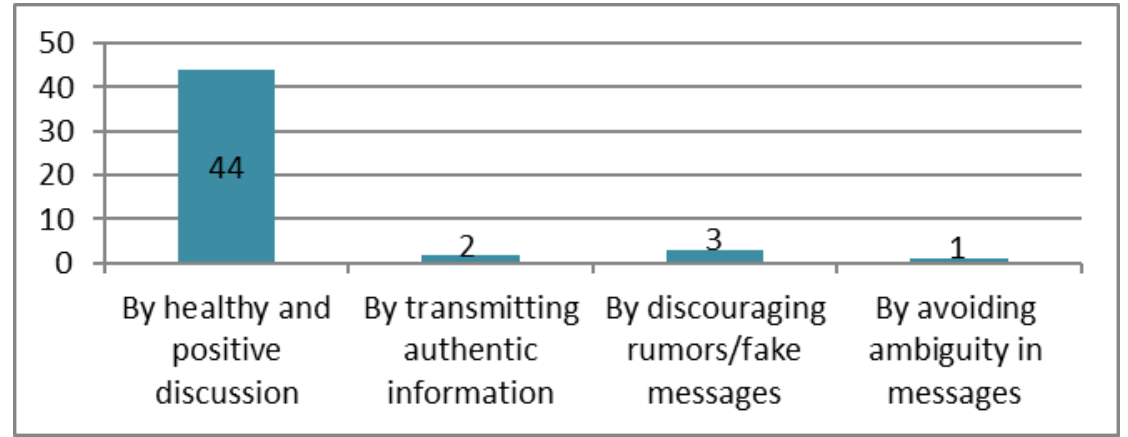

Source: Data collected through questionnaire

Eighty-Eight respondents believe that by healthy and positive discussion, one can understand and promote others culture and it is more psychological in nature as it is linked with understanding the behavior, nature and attitude of others.

Figure 10: What is the nature of WhatsApp messages that you transmit?

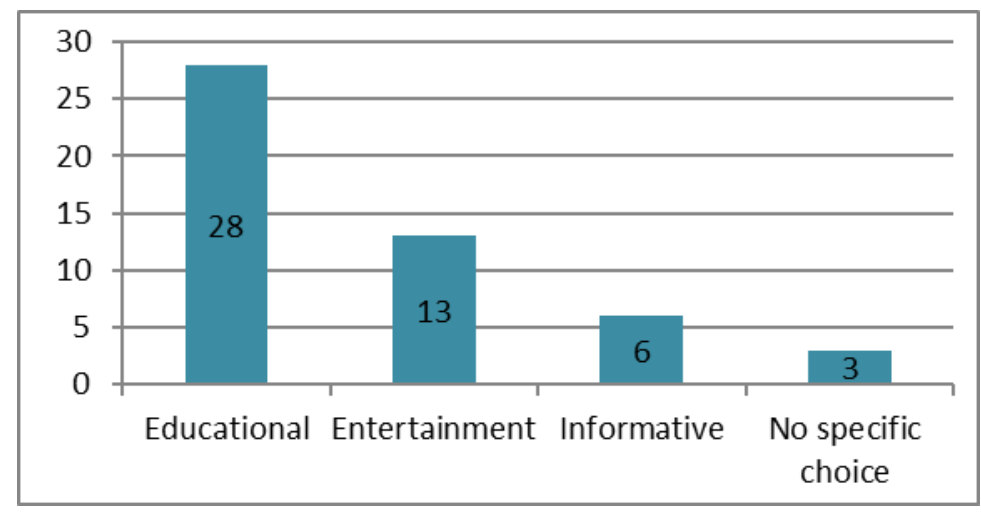

Source: Data collected through questionnaire

Fifty-Five percent of the respondents who are in fact college students through their different sociocultural group share messages ingrained with educational/academic/professional background. The respondents also actively exchange messages related to entertainment as well.

\section{SWOT analysis of WhatsApp in multicultural environment}

SWOT analysis is a management technique which is used to determine strength, weaknesses, opportunities and threats which are involved in any operation or planning so that a concrete decision can be taken to accomplish the set objectives. In this study, SWOT of application of WhatsApp is done on account of interaction that has been made by the researchers with the students during the course of study and is also based on a close study of literature review and results of the study that indicate do's and don'ts of WhatsApp application in language learning process in multicultural environment. 
Table 1: SWOT Analysis based on the result of the study.

\begin{tabular}{|c|c|c|c|}
\hline STRENGTH & WEAKNESS & OPPORTUNITY & THREAT \\
\hline User-friendly & Risk of excessive use & Open-mindedness & Cyber Security \\
\hline Free and easily accessible & Health problems & $\begin{array}{c}\text { Better understanding } \\
\text { of multicultural } \\
\text { diversity }\end{array}$ & Information Theft \\
\hline Time Saving & Rumors & Sharpening LSRW Skills & $\begin{array}{l}\text { Misuse of } \\
\text { technology }\end{array}$ \\
\hline Economical & Authenticity issues & Face to face interaction & Backup Issues \\
\hline Feature of Group Chat & $\begin{array}{c}\text { Reliance on data } \\
\text { plan/wifi }\end{array}$ & Instant messaging & Awareness issues \\
\hline $\begin{array}{l}\text { Feature of various file } \\
\text { formats }\end{array}$ & Not diversified & Active participation & $\begin{array}{l}\text { Malware and } \\
\text { Virus issues }\end{array}$ \\
\hline Audio and Video Calls & Breach of data & Learner-Centric & $\begin{array}{l}\text { Free availability } \\
\text { of Similar } \\
\text { applications }\end{array}$ \\
\hline Available for all Platforms & Promotion of False news & $\begin{array}{c}\text { Growing number of } \\
\text { users }\end{array}$ & $\begin{array}{l}\text { Misuse of data } \\
\text { and pictures }\end{array}$ \\
\hline
\end{tabular}

\section{Proposed classroom activities at the graduate level}

The proposed classroom activities are based on the findings of the study so that a trainer/teacher can conduct them in his/her classroom so as to ensure viable and practical use of WhatsApp. These activities are model activities in which a teacher/trainer may bring variation as per the requirements of the class.

\section{Activity-1}

- The class has to be divided into two groups A and B. A should be forwarded video clips without any dialogues by group $B$ and group $A$ is to be asked to look at the video, prepare the script, read out the script and play the assign roles. The group $B$ will be asked to monitor and evaluate the activity and provide feedback or remark.

\section{Activity-2}

- The whole class will form a WhatsApp group of the students and the group administrator will be the in-charge teacher and he/she will post a passage and student are asked to read and record the passage and write the passage on similar theme as per their understanding of the passage and its interwoven culture. In order to bring variation in the activity, the teacher can also ask the students to record their video in relation to recital of any poem, conversation from any literary article and compare it with the standard version available on social platform or Multimedia tools like YouTube.

\section{Activity-3}

- The whole class will form a WhatsApp group and the group administrator can organize group activities such as Role-play, Reading Paragraphs, and Poetry Recital, Writing messages or small piece of prose. The administrator can also forward quotes, capsule novels, small poems, short stories and the like.

\section{Conclusions and suggestions}

As already stated, very few studies have been attempted on application of using WhatsApp in enhancing language learning. So, only few aspects have been explored by previous studies like as using games for Language Learning, using audio-video tools, or making class interactive through video callings but nothing systematic/ practical aspects have been highlighted by the studies done earlier. In this 
direction, the present research study may be very useful for pedagogical objectives. The results of the study indicate that the application of WhatsApp as a learning tool can prove to be highly beneficial in multicultural environment. It helps in the development of mutual respect for each other's culture. It reunites learners of different cultures, religions, origins and different ideologies. Its applications help in understanding cultural and linguistic diversity. It reduces stereotype thinking and develops creative, original and broad thinking. It helps the learners to work in collaboration so that they can understand and share their information in more natural and rational manner among their peer group and can seek guidance or clarification from their trainers as well. It provides them real life experiences on their fingertips. Respect for cultural values is the foundation stone for developing a perfect multicultural environment for making learning process smooth. Exchange of information takes place on language scale as well as cultural scale. By using applications like WhatsApp, it is reflected in this study that students become more aware about their mother tongue and target culture as well. Learning becomes more learner-centric if they learn in a diverse and dynamic leaning environment. Learners show more empathy, become more concerned about their as well as others liking and disliking, temperament, attitude, psychology, interest, manners, socio-cultural norms and values and thus prepare themselves to face the ever-growing challenges of multilingual and multicultural environment.

The study also finds that a teacher/trainer can make his/her language class more interesting and happening by using WhatsApp application in promoting discussions and debates. WhatsApp may prove to be a boon for enhancing Listening, Speaking, Reading, Writing Skills as it has ample scope and space for making information live, attractive, interesting and meaningful. The results show that a good number of students not using neither English nor Hindi but combination of both i.e. Hinglish. In such case, it is quite challenging for the teachers to shift their focus on using English but as they are already using certain terms, phrases and expressions in English and hence it requires only proper guidance, encouragement and motivation from the teachers' end to use English more than Hinglish which may not be useful for them in their personal and professional endeavors rather it may prove to be obstacle for their all-round growth in this globalized world. It helps the learners to improve their LSRW skills in group in collaboration. Teachers can enhance active participation of his/her learners by providing them assignments, tests and other elite tasks. Vocabulary of the students can also be increased and grammatical errors can be downsized. Lexical, morphological and syntactical activities can be multiplied in this multicultural environment. Obtaining feedback is convenient and proper monitoring of language learning activities can be made easy.

A teacher can also extend his/her availability by use of this application. Otherwise, in traditional classes, teaching hours are fixed. Irrelevant information can be monitored by the Group administrator and necessary instructions can be passed to the participants to discuss only relevant issues. WhatsApp has brought new features in which the Group Administrator can restrict the sending of messages and only administrators can be able to send the information. Moreover, administrator can block and report the participant for posting irrational and irrelevant information which may cause impediment in the process of learning. Posted Information, if does not match the interest and liking of the participant can also deleted. For online/distance-learning applications of WhatsApp, appears to be boon for both the teachers and learners as well. Student can also be benefitted by keeping certain restrictions in mind. It is well said that excess is bad if it is used beyond the limit and it may cause certain harms to the learners like restlessness, anxiety, less physical activities and issues leading to severe vision problems. Use of WhatsApp is increasing amidst students and along with various advantages it has limitations too. Despite of its limitations, students spared their time on WhatsApp rather in any other physical activity. So, they have to be very cautious while using this application for boosting their confidence and reducing their hesitation towards language learning in multicultural environment. Students should be encouraged to post their views, ask their questions, and clarify their doubts and to provide their feedback on the raised issues and during the exchange of any information. Involvement of good number of participants enables 
them to develop inter-cultural understanding. It is also noted in the study that students also become interested in understanding reading comprehensions and become friendly towards their fellow participants.

The results of the study highlight that most of the respondents agree that WhatsApp helps in acknowledging culture and tradition. The application of WhatsApp also promotes certain qualities among learners such as tolerance, open-mindedness, and listening with patience. Similarly, a teacher can also inculcate an environment of collaborative learning by becoming attentive and active during his/her teaching process. By posting positive and constructive messages in relation to language learning, teachers and students can develop a holistic multicultural environment based on trust, honesty, integrity, reliability, transparency. Application of WhatsApp is found very handy in multicultural environment as it serves multifaceted purposes to share information and messages in diverse cultural background. This is also evident to note that combination of both text and multimedia is quite imperative for developing better understanding and bond of relationship among the participants in the backdrop of multicultural setting. The results of the study proved that WhatsApp can be used as a pedagogical tool for enhancing language learning skills in a multicultural environment. Thus, application of WhatsApp can be an ideal and perfect match in today's context if it is used judiciously and with utmost care; it will facilitate ample space for acceptance of multicultural and multilingual identities and it will cultivate a sense of better understanding for others culture, social norms and traditional values. Ethical and value based communication is the need of the hour as it will help people to connect with more trust, transparency and reliability.

\section{Limitations}

The study has been conducted with a small number of samples due to paucity of time and in order to make it more competent it is restricted to city of Bhopal.

\section{Future scope of the study}

Similar studies can be conducted by exploring cultural issues/ conflict/ variation through usage of other multimedia/social platform tool such as Twitter, Facebook, Instagram and so on. Empirical studies can be attempted to assess the performance of the learners before the induction of such technology/software enabled tools and to evaluate the performance after induction of the same. So, a comparative analysis can be obtained and their outcome may be very helpful for application and monitoring of such tools.

\section{References}

Ayuningtyas, P. (2018). WhatsApp: Learning on the Go. Metathesis: Journal of English Language Literature and Teaching, 2 (2), 159-163.

Bansal, T. \& Dhananjay, J. (2014). A Study of Students' Experiences of Mobile Learning. Global Journal of HumanSocial Science: Interdisciplinary, 14 (4), 26-33.

Bensalem, E. (2018). The Impact of WhatsApp on EFL Students' Vocabulary Learning. Arab World English Journal, 9 (1), 23-38.

Dweikat, K. (2018). EFL Students' Perceptions of WhatsApp and its Potential Benefits in ELT Practicum. Palestinian Journal of Technology and Applied Sciences, (2), 14-29.

Fattah, S. (2015). The Effectiveness of Using WhatsApp Messenger as one of Mobile Learning Techniques to Develop Students' Writing Skills. Journal of Education and Practice, 6 (32), 115-127.

Hamad, M. M. (2017). Using WhatsApp to Enhance Students' Learning of English Language "Experience to Share". Higher Education Studies, 7 (4), 74-87.

Hrodrigues (2008). Sanskrit Grammarians: Indian Grammarians and the Philosophy of Sound. Http://www.mahavidya.ca/2008/06/21/indian-grammarians-and-the-philosophy-of-sound/. $\quad$ (10 December, 2019). 
Justina, M. (2016). Use of WhatsApp to Enhance Reading and Writing Skills at Undergraduate College Level. Language in India, 16 (11), 47-60.

Kacetl, J. \& Klímová, J. (2019). Use of Smartphone Applications in English Language Learning-A Challenge for Foreign Language Education. Education Sciences, 9 (179), 1-9.

Kumar, N. \& Sudhansh, S. (2016). Survey Analysis on the Usage and Impact of WhatsApp Messenger. Global Journal of Enterprise Information System, 8 (3), 52-57.

Mehta K. N. (2012). Mobile Phone Technology in English Teaching: Causes and Concerns. MJAL, 4 (2), $82-92$.

Patel, C. (2013). Use of Multimedia Technology in Teaching and Learning communication skill: An Analysis. International Journal of Advancements in Research and Technology, 2 (7), 116-122.

Penguin Books. Dictionary of Literary Terms and Literary Theory. 2013, 449-450.

Rahman, A., Patintingan, A. \& Indahyanti, R. (2018). Learning beyond the Classroom: WhatsApp in Language Learning. Exposure Journal, 7 (2), 71-89.

Rathore, M. \& Mehta, N. (2015). Sharpening Communication Skills of Engineering Students via Multifaceted Digital Tools: A Conceptual Framework. Journal of Advances in English Language Teaching, 3 (4), 82-89.

Srilakshminarayana, G. (2016). An Exploratory Study on Usage of WhatsApp among the Undergraduate and the Post-Graduate Students of Mysore. Applied Research Series, Mysuru.

Ta'amneh, M. (2017). The Effect of Using WhatsApp Messenger in Learning English Language among University Students. International Research in Education, 5 (1), 143-151. 